\title{
STUDIES ON STAPHYLOCOCCI FROM HOSPITAL PATIENTS. I. PREDOMINANCE OF STRAINS OF GROUP III PHAGE PATTERNS WHICH ARE RESISTANT TO MULTIPLE ANTIBIOTICS 1, 2
}

\author{
BY VERNON KNIGHT AND ANNA R. HOLZER \\ (From the Department of Medicine, Cornell University Medical College, and Cornell Medical \\ Division, Bellerue Hospital, New York, N. Y.)
}

(Submitted for publication January 21, 1954 ; accepted May 14, 1954)

Studies from widely separated geographical areas (1-5) have revealed that a great majority of staphylococci from hospital patients which are resistant to penicillin are lysed by group III staphylococcal bacteriophages. Furthermore, in two of these studies $(2,5)$, it was found that strains of staphylococci found to be resistant to tetracyclines were also resistant to penicillin and lysed by group III phages. Since group III bacteriophages were named because they lysed staphylococci of Cowan's serologic group III, it appeared that one biologic subdivision of human pathogenic staphylococci was the chief source of strains from hospital patients in several areas which were resistant to antibiotics.

At Bellevue Hospital in 1953-54, these observations were confirmed, and it was additionally found here that resistance to streptomycin was also a characteristic of this group of staphylococci.

Evidence was obtained that this phenomenon probably resulted from the widespread use of antibiotics in hospitals, when it was found that staphylococci isolated at a nearby hospital in the period $1932-48$, at a time when, for the most part, no antibiotics were available, exhibited few of the characteristics described above. Moreover, based on a study of strains isolated from patients soon after admission to Bellevue Hospital in 1953-54, it was determined that multiple drug resistance and lysis by group III phages were not important characteristics of staphylococci carried by non-

1 Presented in part before the Antibiotics Symposium of the Food and Drug Administration, Department of Health, Education and Welfare, Washington, D. C., October, 1953.

2 This investigation was supported by grants from Charles Pfizer and Company, Brooklyn, New York; Parke, Davis and Company, Detroit, Michigan; and by a research grant (E-330) from the National Institutes of Health, Public Health Service, Bethesda, Maryland. hospitalized persons, to whom antibiotics are less frequently administered. Finally, it was found that the rate at which newly hospitalized patients acquired staphylococci characteristic of the hospital was correlated with the kind of antimicrobial treatment they received.

The report which follows consists of a description of these studies.

\section{PLAN OF STUDY}

\section{Clinical material}

Cultures for staphylococci were made three times weekly of the nose, throat, and rectum of a large number of patients at Bellevue Hospital with non-staphylococcal illness. From about one-half of them, a total of 80 patients, were obtained cultures of staphylococci (Micrococcus pyogenes var. aureus). Sixty-seven of the patients who had infectious diseases, principally pneumococcal pneumonia, were treated as follows: 30 were given penicillin alone or in combination with streptomycin; 25 received chlortetracycline or oxytetracycline; and 12 got other combinations of antibiotics. Thirteen patients with non-infectious illnesses, including cases of duodenal ulcer, cirrhosis of the liver, hepatitis, and heart disease, received no antimicrobial therapy. From these 80 patients were obtained $\mathbf{4 1 4}$ strains of staphylococci.

Six additional patients with serious staphylococcal infection were included in the study, and from them 102 strains of staphylococci were obtained, 24 of which were cultured from blood or localized staphylococcal lesions. The characteristics of strains from these patients were generally similar to those from non-staphylococcal cases.

Fifty-five strains of staphylococci (Micrococcus pyogenes var. aureus) which had been collected at Postgraduate Hospital in New York ${ }^{8}$ in the period 1932-48 were also available for this investigation. Thirty-nine strains were cultured from blood and the remainder were from other sites of staphylococcal infection.

8 These strains were collected by the late Dr. Ward MacNeil and Miss Anne Blevins, and were preserved by Dr. John Blair, Hospital for Joint Diseases, New York City, who has kindly provided subcultures for use in this investigation. 
TABLE I

Susceptibility of staphylococcus aureus to antibiotics $\begin{array}{llr}1932-48 & \text { Postgraduate Hospital Collection } & 55 \text { strains } \\ 1953-54 & \text { Belleoue Hospital Collection } & 516 \text { strains }\end{array}$

\begin{tabular}{|c|c|c|c|c|c|c|c|c|c|c|}
\hline & \multicolumn{2}{|c|}{$\begin{array}{l}\text { Per cent } \\
\text { sensitive }\end{array}$} & \multicolumn{2}{|c|}{$\begin{array}{l}\text { Per cent } \\
\text { mod. sens. }\end{array}$} & \multicolumn{2}{|c|}{$\begin{array}{l}\text { Per cent } \\
\text { mod. resist. }\end{array}$} & \multicolumn{2}{|c|}{$\begin{array}{l}\text { Per cent } \\
\text { resistant }\end{array}$} & \multicolumn{2}{|c|}{$\begin{array}{l}\text { Per cent } \\
\text { highly resist }\end{array}$} \\
\hline & Postgrad & Bell. & Postera & Bell. & Postgrac & Bell. & Postgr & Bell. & Postgra & Bell. \\
\hline & \multicolumn{2}{|c|}{0.1} & \multicolumn{2}{|c|}{1.0} & \multicolumn{2}{|c|}{10} & \multicolumn{2}{|c|}{25} & $\because$ & \\
\hline \multirow[t]{2}{*}{ Penicillin } & 78 & 14.9 & 4 & 0.7 & 2 & 7 & 9 & 5.4 & 7 & 72.2 \\
\hline & Mas./ml. & & 6 & $\because$ & \multicolumn{2}{|c|}{25} & \multicolumn{2}{|c|}{50} & \multicolumn{2}{|c|}{$>50$} \\
\hline $\begin{array}{l}\text { Chlortetracycline } \\
\text { Oxytetracycline } \\
\text { Streptomycin } \\
\text { Chloramphenicol }\end{array}$ & $\begin{array}{r}100 \\
100 \\
4 \\
2\end{array}$ & $\begin{array}{c}32.8 \\
34 \\
0.7 \\
4.5\end{array}$ & $\overline{-}$ & $\begin{array}{c}0.8 \\
0 \\
10.5 \\
37.8\end{array}$ & $\begin{array}{l}- \\
\overline{56} \\
82\end{array}$ & $\begin{array}{l}0.7 \\
0.4 \\
19.4 \\
31\end{array}$ & $\frac{-}{4}$ & $\begin{array}{c}1 \\
0 \\
2.7 \\
17.4\end{array}$ & $\overline{-}$ & $\begin{array}{r}65 \\
65.5 \\
66.7 \\
9.1\end{array}$ \\
\hline & \multicolumn{2}{|c|}{ Mcg./ml. } & \multicolumn{2}{|c|}{1.6} & \multicolumn{2}{|c|}{6} & \multicolumn{2}{|c|}{25} & \multicolumn{2}{|c|}{$>25$} \\
\hline Erythromycin & 89 & 97 & 11 & 0.7 & - & 0.3 & - & 0.7 & - & 1 \\
\hline
\end{tabular}

\section{Microbiologic procedures}

Isolation of Staphylococcus aurews. Nose, throat, and rectal swabs were streaked on plates of trypticase soy agar containing 0.25 phenyl ethyl alcohol, and the rectal swab was later incubated in a tube of Brewer's thioglycollate broth. A subculture was made of a representative colony of staphylococcus from each culture, which fermented mannitol, hemolyzed equine or human red cells, and coagulated citrated human plasma, and was preserved for the study. In the event that no colonies resembling staphylococci were found on plates inoculated with rectal swabs, the thioglycollate broth was examined, and very exceptionally it yielded strains of staphylococci with the above characteristics.

Susceptibility to antibiotics. The technic described by Jackson and Finland (6), employing agar plate dilutions, was used to test the susceptibility of the strains to antibiotics.

Penicillinase production test. The procedure described by Gots and modified by Haight and Finland (7) was used to test for penicillinase production of 398 of the strains of staphylococcus in this study. There was a close correlation between resistance to penicillin and production of the enzyme by strains of staphylococcus. Since these findings correspond closely to observations by many others, no further description of the results will be made.

Determination of patterns of lysis of staphylococci by bacteriophage (phage typing). The methods of phage typing described by Williams and Rippon (8) and by Blair and Carr (9) were used in this study. The procedure consisted of exposing strains of staphylococci to be identified (typed) to a series of staphylococcal bacteriophages in certain specified dilutions. If a strain was not lysed by any of the diluted bacteriophage suspensions, it was retested with undiluted bacteriophage. In the present investigation, 54 per cent of 516 strains exhibited patterns of lysis when exposed to bacteriophages in specified dilutions, and an additional 41 per cent were lysed when retested with undiluted phage. Only 5 per cent of strains were not lysed (untypable) in the study.

Twenty-five different staphylococcal bacteriophages were used in the investigation. 4 They were divided into three series according to their capacity to lyse strains of staphylococci of Cowan's serologic groups, as follows: Cowan's staphylococcal group I, phages 52, 52a, 29, 29a, $31,44,44 a$; Cowan's group II, phages $3 a, 3 b, 3 c, 51,39$, 523; Cowan's group III, phages $6,7,42 \mathrm{~b}, 42 \mathrm{~d}, 42 \mathrm{e}, 47$, 47b, 47c, VA4; and unclassified, 42c, 47a, and 142.

Staphylococcal strains were designated as members of phage group I, II, or III, according to their susceptibility to lysis by the respective groups of bacteriophages. There was a small amount of overlapping of reactions among the three groups, especially when undiluted phages were used, but there was rarely any difficulty in picking out the phage groups with the predominating lytic reactions.

\section{RESULTS}

Comparison of antimicrobial susceptibility and phage patterns of staphylococci collected at Postgraduate Hospital in the period 1932 to 1948, with strains isolated at Bellevue Hospital in 1953 and 1954

Susceptibility to antimicrobial agents (Table I). The Postgraduate Hospital collection of 55 strains of staphylococci were all found to be highly susceptible to the tetracyclines and erythromycin. Approximately three-fourths were highly susceptible to penicillin, while chloramphenicol and streptomycin inhibited most strains in concentrations in the intermediate range of susceptibility.

4 The bacteriophages and the propagating strains of staphylococci were kindly provided by Dr. John Blair. 
In contrast, almost three-fourths of the Bellevue Hospital strains of staphylococci were highly resistant to penicillin, and two-thirds were highly resistant to the tetracyclines and streptomycin. There was little difference in susceptibility to chloramphenicol and erythromycin from the 193248 collection, except for the presence of a few strains which had been observed to become resistant to the latter drug after exposure to it in treatment.

Correlations of resistance and susceptibility to the various antibiotics among the Bellevue $\mathrm{Hos}^{-}$

TABLE II

Correlations among grades of susceptibility to four antibiotics

\begin{tabular}{|c|c|c|c|}
\hline & . & No. strains & Per cent \\
\hline Resistant* to & $\begin{array}{l}\text { Penicillin } \\
\text { Streptomycin } \\
\text { Tetracycline } \\
\text { derivatives }\end{array}$ & 338 & 65.5 \\
\hline & $\begin{array}{l}\text { Penicillin } \\
\text { Streptomycin }\end{array}$ & & \\
\hline Sensitive $\nmid$ to & $\begin{array}{c}\text { Tetracycline } \\
\text { derivatives }\end{array}$ & 75 & 14.5 \\
\hline Resistant to & $\begin{array}{l}\text { Penicillin } \\
\text { Tetracycline } \\
\text { derivatives }\end{array}$ & & \\
\hline Sensitive to & Streptomycin & 1 & .2 \\
\hline $\begin{array}{l}\text { Resistant to } \\
\text { Sensitive to }\end{array}$ & $\begin{array}{l}\text { Penicillin } \\
\text { Streptomycin } \\
\text { Tetracycline } \\
\text { derivatives }\end{array}$ & 25 & 4.9 \\
\hline $\begin{array}{l}\text { Sensitive to } \\
\text { Resistant to }\end{array}$ & $\begin{array}{l}\text { Penicillin } \\
\text { Streptomycin } \\
\text { Tetracycline } \\
\text { derivatives }\end{array}$ & 3 & .6 \\
\hline Sensitive to & $\begin{array}{l}\text { Penicillin } \\
\text { Tetracycline } \\
\text { derivatives }\end{array}$ & & \\
\hline Resistant to & Streptomycin & 43 & 8.3 \\
\hline & $\begin{array}{l}\text { Penicillin } \\
\text { Streptomycin }\end{array}$ & & \\
\hline Resistant to & $\begin{array}{c}\text { Tetracycline } \\
\text { derivatives }\end{array}$ & 1 & .2 \\
\hline Sensitive to & $\begin{array}{l}\text { Penicillin } \\
\text { Streptomycin } \\
\text { Tetracycline } \\
\text { derivatives }\end{array}$ & 30 & 5.8 \\
\hline Total & & 516 & 100 \\
\hline
\end{tabular}

* Resistant: Penicillin-1 to >25 mcg. per ml.; chlorand oxytetracycline, streptomycin not inhibited by less than 25 mog. per ml.

+ Sensitive: Penicillin- $0.1 \mathrm{mcg}$. per ml.; chlor- and oxytetracycline, streptomycin-6 mcg. per ml. or less. pital strains revealed (Table II) that about twothirds of the 516 strains were resistant to the four antibiotics, penicillin, chlortetracycline, oxytetracycline, and streptomycin. Among the remaining strains, the only recognizable pattern was a tendency toward association of resistance to penicillin and streptomycin.

Patterns of lysis of staphylococci by bacteriophages. In Table III is shown the bacteriophage patterns (phage types) of the staphylococci collected in the interval 1932 to 1948, classified according to phage grouping I, II, or III. The per cent of strains in each group resistant to penicillin, the tetracyclines, and streptomycin is indicated. Only 20 per cent of the 55 strains were of phage group III patterns, yet more than one-half of all strains resistant to penicillin were in this group. Furthermore, as a point to be discussed later, it was found that five of these latter strains were isolated after penicillin was generally in use in hospitals.

Among the 516 strains from Bellevue Hospital (Table IV), three-fourths were in phage group III and, of these, 89 per cent were resistant to penicillin and 82 per cent were resistant to the tetracyclines and streptomycin. Consequently, more than 90 per cent of strains of staphylococcus resistant to penicillin, the tetracyclines, and streptomycin, singly or collectively, were of group III phage patterns.

Comparison of the rate of appearance in patients during hospitalization of staphylococci of group III phage patterns resistant to penicillin, the tetracyclines, and streptomycin

The studies just described showed that strains of group III phage patterns resistant to multiple antibiotics constituted a large majority of a large sample of staphylococci from patients at Bellevue Hospital in 1953 and 1954. In studies to follow, it will be shown that a negligible number of such strains were present in cultures taken during the first three hospital days (strains presumed to have been brought to the hospital by the patients).

On the basis of these observations, it was suggested that staphylococci of group III phage patterns resistant to multiple antibiotics which appeared in patients during hospitalization were acquired from sources within the hospital, and they 
TABLE III

Phage patterns and antibiotic susceptibility of 55 strains of staphylococcus aureus Postgraduate Hospital Collection 1932-1948*

\begin{tabular}{|c|c|c|c|c|}
\hline \multirow{2}{*}{ strains } & \multirow[b]{2}{*}{ Per cent } & \multirow[b]{2}{*}{ Phage pattern } & \multicolumn{2}{|c|}{$\begin{array}{c}\begin{array}{c}\text { Penicillin resistance } \\
\text { Range } 1.0 \quad 25 \text { mcg. } / \mathrm{ml}\end{array} \\
\end{array}$} \\
\hline & & & No. strains & Per cent \\
\hline \multicolumn{5}{|c|}{ Group III } \\
\hline 8 & & $\begin{array}{lllllll}6 & 7 & 42 \mathrm{~b} & 47 & 47 \mathrm{c} & \mathrm{VA} 4 & 42 \mathrm{e}+\dagger\end{array}$ & $5(1940,1946$, & \\
\hline $\begin{array}{l}2 \\
1\end{array}$ & & $\begin{array}{l}\text { VA4 } \\
42 \mathrm{c} \quad 42 \mathrm{~d}\end{array}$ & $1(1948)$ & \\
\hline$\overline{11}$ & 20 & & 6 & 54 \\
\hline 3 & 5 & Untypable & $1(1944)$ & 33 \\
\hline \multicolumn{5}{|c|}{ Group I } \\
\hline $\begin{array}{r}12 \\
5 \\
12\end{array}$ & & $\begin{array}{ll}52 \mathrm{a} & 52+ \\
29 & 31+ \\
44 \mathrm{a} & 42 \mathrm{e} \ddagger\end{array}$ & $\begin{array}{l}2(1938,1948) \\
1(1940) \\
1(1938)\end{array}$ & \\
\hline$\overline{29}$ & 53 & & $\overline{4}$ & 14 \\
\hline \multicolumn{5}{|c|}{ Group II } \\
\hline $\begin{array}{l}6 \\
3 \\
1\end{array}$ & & $\begin{array}{rrr}3 a & 3 b & 3 c+ \\
& 39 & \\
& 523 & \end{array}$ & 1 (1948) & \\
\hline$\overline{10}$ & 18 & & $\overline{1}$ & 10 \\
\hline \multicolumn{5}{|c|}{ Unclassified } \\
\hline 2 & & $\begin{array}{llll}42 \mathrm{~b} & 44 \mathrm{a} & 42 \mathrm{e} & 47 \mathrm{c}+\end{array}$ & & \\
\hline$\overline{2}$ & 4 & & & \\
\hline 55 & 100 & & 12 & 22 \\
\hline
\end{tabular}

* All strains were inhibited by $3 \mathrm{mcg} . / \mathrm{ml}$. of chlortetracycline and oxytetracycline, and those not otherwise indicated were inhibited by $0.1 \mathrm{mcg} . / \mathrm{ml}$. of penicillin.

$t(+)$ indicates additional weak lytic reactions were present.

$\ddagger$ Williams and Rippon state that $42 \mathrm{e}, 7,47 \mathrm{c}$ may occur with group I phages.

are subsequently referred to as "hospital staphylococci." Furthermore, it was found that important differences in the rate at which these strains were acquired by patients could be correlated with the antimicrobial treatment which they received.

Patients treated with tetracyclines (Figure 1a) acquired "hospital staphylococci" most rapidly. From a value of 16.6 per cent on admission ( 1 to 3 days), the percentage increased to 90 per cent by the 4- to 5-day period, and thereafter increased to 100 per cent during the 12- to 13- and 14- to 15day periods. Treatment with penicillin (Figure 1b) was associated with a later and lesser rise in the per cent of "hospital staphylococci" reaching 29 per cent in the 6- to 7-day period and 65 per cent in the 8- to 9-day period. During the following six days, some further increase in the per cent of "hospital staphylococci" was noted.
The group of patients who received no antimicrobial therapy (Figure 1c) showed the lowest rate of acquisition of "hospital staphylococci." During the first three hospital days no "hospital staphylococci" were recovered, and subsequently there were only sporadic elevations in the percentage, ranging from 20 to 43 , all values far below the per cent of such strains isolated from antibiotic treated patients.

The per cent of strains in each therapy group resistant to penicillin and the tetracyclines are also shown in Table $\mathrm{V}$ and Figure $1 \mathrm{a}, \mathrm{b}, \mathrm{c}$. These data reveal that practically all strains resistant to the tetracyclines were in the category of "hospital staphylococci," and, based on the low per cent of these strains isolated in the first three hospital days, it appears that the non-hospital population 
TABLE IV

Phage patterns and antibiatic resistance of 516 strains of Staphylococcus aureus Belleone Hospital Collection 1953-1954

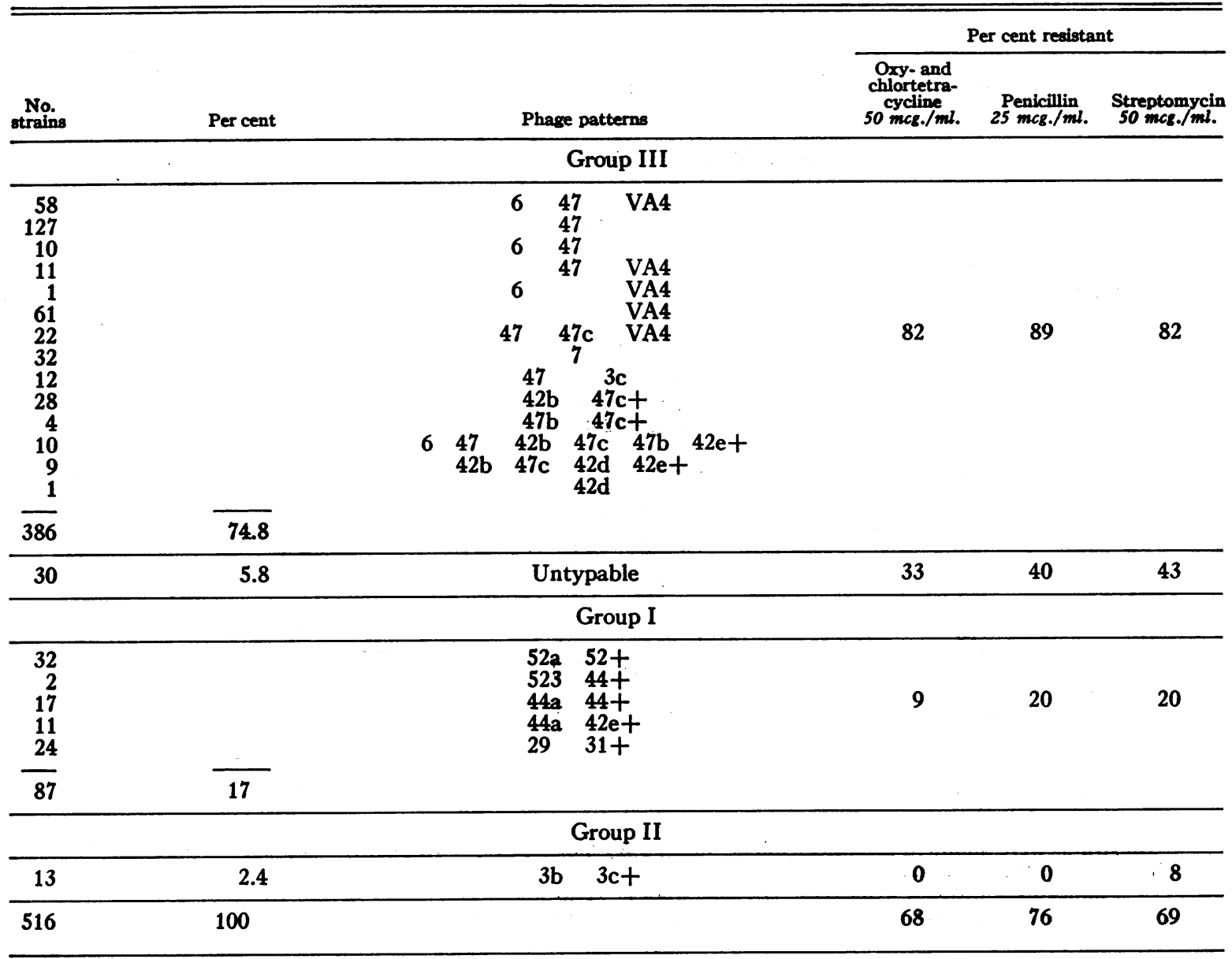

may not carry many staphylococci resistant to the tetracyclines. In contrast, a majority of staphylococci resistant to penicillin isolated during the first three hospital days were not "hospital staphylococci," and were found to consist principally of phage group I strains. Since about one-half of all admission strains were penicillin resistant, it appeared that a considerable reservoir of staphylococci of phage group I, which were resistant to penicillin, existed in the general population. Many of these penicillin resistant strains which were not classifiable as "hospital staphylococci" continued to be carried by patients during hospitalization who received penicillin or no treatment, but among patients treated with tetracyclines they were replaced by "hospital staphylococci."
DISCUSSION

The foregoing studies have revealed that approximately two-thirds of a large number of strains of staphylococci principally obtained from cultures of the nose, throat, and rectum of staphylococcal carriers at Bellevue Hospital in 1953-54, were highly resistant to penicillin, the tetracyclines, and streptomycin. Moreover, more than 90 per cent of these staphylococci which were resistant to multiple antibiotics were of group III phage patterns.

In marked contrast, among 55 strains of staphylococci collected in the period $1932-48$ at Postgraduate Hospital, all were susceptible to the tetracyclines, most were susceptible to penicillin, and the majority were inhibited in the intermediate 
range of susceptibility by streptomycin. It is considered that the susceptibility to streptomycin and to the tetracyclines represents about the usual behavior of these organisms with this agent. The small per cent of these staphylococcus strains showing resistance to penicillin, nevertheless, was higher than would have been expected. More than half of these few penicillin resistant staphylococci were of phage group III, and most of them had been isolated after probable exposure to penicillin. Thus it appeared that the correlation between drug resistance of staphylococcal strains and lysis by group III phages, so evident in the 1953-54 collection, was also present to a degree among the strains of the $1932-48$ collection, probably as a result of exposure to penicillin.

Other studies revealed that strains of staphylococci of group III phage patterns resistant to several antibiotics were found infrequently in patients during the first three hospital days (i.e., staphylococci presumed to have been brought to the hospital), in contrast to their high predominance in the hospital population in general. Furthermore, it was found that the rate of acquisition of "hospital staphylococci". was greatest among patients treated with tetracyclines, second among patients treated: with penicillin, and least among patients who received no antimicrobial therapy.

These events may be tentatively explained in the following way. It was found that a large majority of staphylococci isolated on admission to the hospital were susceptible to tetracyclines, while only about one-half were susceptible to penicillin. Within the hospital, however, was a large reservoir of staphylococci resistant to both tetracyclines and penicillin. It appeared that the large proportion of staphylococci carried on admission which were susceptible to tetracyclines, were eliminated by treatment with these agents, and were subsequently replaced by resistant strains from the reservoir in the hospital. A similar but less extensive change apparently took place with respect to penicillin,

TREATMENT WITH TETRACYCLINES

25 PATIENTS IIS STRAINS

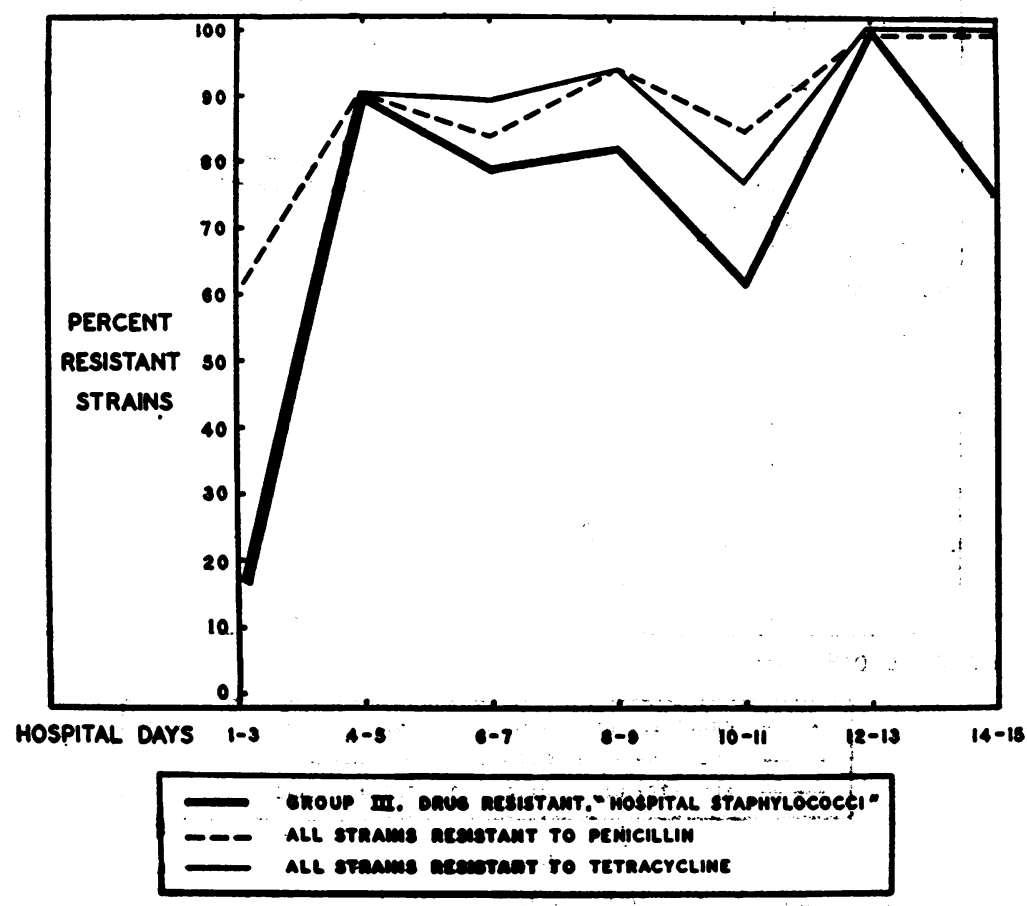

Figure 1a

The per cent of staphylococci of group III phage patterns resistant to chlortetracycline, oxytetracycline, penicillin, and streptomycin ("hospital staphylococci") increased from a negligible percentage on : admission to a large majority by the 4-to 5-day period, and thereafter remained high. 
since only one-half of the staphylococci carried at admission were susceptible to this agent. Among patients receiving no antimicrobial treatment, there was no impetus toward elimination of strains carried on admission, whether susceptible or resistant, so that there was virtually no replacement phenomenon, and acquisition of "hospital staphylococci" was very gradual.

A paradoxical phenomenon observed in these studies was the finding that resistance to penicillin increased significantly more rapidly among strains from patients exposed to tetracyclines in treatment than among strains from patients treated with penicillin. This apparently occurred because of the fact that staphylococci resistant to tetracyclines were also resistant to penicillin, and the higher rate of increase in resistance to tetracyclines was necessarily associated with a similar increase in resistance to penicillin.
The observations which have been presented in this report raise the fundamental question as to why a particular biologic subdivision of human pathogenic staphylococci has become the major source of strains resistant to antibiotics among hospital patients in several areas. Resistance of staphylococci to antibiotics is by no means a unique property of staphylococci of phage group III, and in the present investigation a large proportion of the approximately 60 per cent of strains resistant to penicillin cultured from patients soon after admission were of group I phage patterns. Although the coincident occurrence of the great majority of staphylococci resistant to other antibiotics in phage group III may be indicative of some special property of these staphylococci, it also follows very logically that, if group III strains predominated in an institution as a result of the use of penicillin,

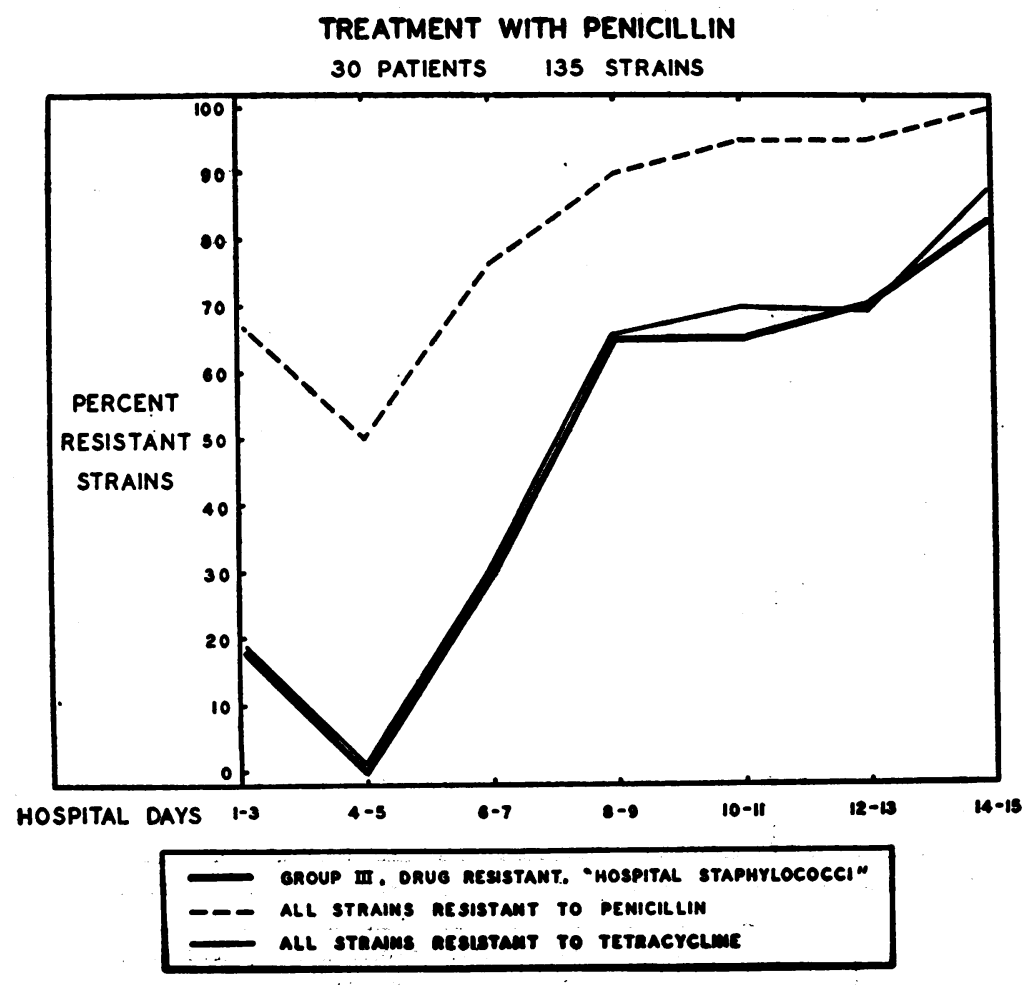

FIGURe 1b

The per cent of "hospital staphylococci" increased less rapidly among strains from patients treated with penicillin than among strains from patients treated with tetracyclines. The per cent of strains resistant to penicillin (including those classifiable as "hospital staphylococci") increased less rapidly among the patients who were treated with penicillin than among those strains isolated from patients treated with tetracyclines. 


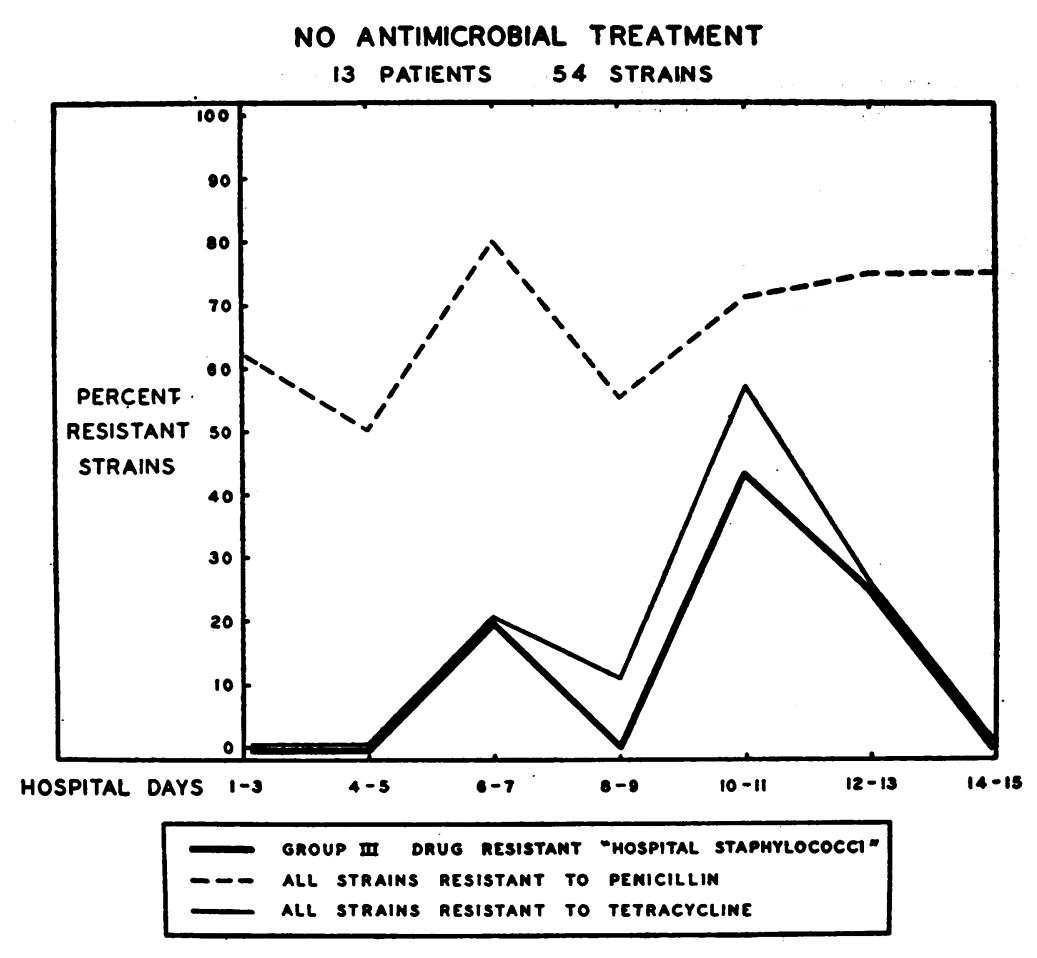

Figure 1c

There was only a moderate rise in the per cent of "hospital staphylococci" among strains isolated from patients receiving no antimicrobial therapy.

resistance to other antibiotics introduced later would be greatest among these same strains.

By this line of reasoning one is led to consider the possibility that concentration of staphylococci resistant to antibiotics in phage group III may result from an effect of penicillin which is peculiar to its use in hospitals. Possible characteristics of the administration of penicillin in hospitals which may be important in this regard are the great frequency of its use and the high doses which are given to individual patients. This explanation would not exclude the possibility that there is some property of staphylococci, present to a greater degree among strains of group III phage patterns, which causes their selection in this situation.

\section{SUMMARY}

In a study of 516 strains of Staphylococcus aureus (Micrococcus pyogenes var. aureus), principally cultured from the nose, throat, and rectum of staphylococcal carriers at Bellevue Hospital in 1953 and 1954, it was found that 65 per cent were resistant to the four antibiotics, chlortetracycline, oxytetracycline, streptomycin, and penicillin. More than 90 per cent of these drug-resistant strains were of phage group III patterns. The strains of staphylococci were of intermediate degrees of susceptibility to chloramphenicol, and nearly all were highly susceptible to erythromycin.

In contrast, 55 similar strains collected in the period 1932 to 1938 were to a large extent susceptible to penicillin, and were all inhibited by low concentrations of the tetracyclines and erythromycin. They were of intermediate degrees of susceptibility to streptomycin and chloramphenicol, and only 20 per cent were in phage group III.

Few staphylococci of group III phage patterns resistant to multiple antibiotics were isolated on admission from staphylococcal carriers at Bellevue Hospital, but thereafter, among such patients who were treated with tetracyclines, these "hospital staphylococci" rapidly replaced other strains of staphylococci. Cultures from patients treated with penicillin underwent a similar but significantly 
TABLE V

Per cent of staphylococci of group III phage patterns resistant to multiple antibiotics, per cent resistant to penicillin, and per cent resistanit to tetracyclines by day of isolation at Bellevue Hospital in 1953-54

\begin{tabular}{|c|c|c|c|c|c|c|c|}
\hline \multirow{2}{*}{$\begin{array}{l}\text { Day of } \\
\text { isolation }\end{array}$} & \multirow{2}{*}{$\begin{array}{l}\text { Total } \\
\text { strains }\end{array}$} & \multicolumn{2}{|c|}{$\begin{array}{l}\text { Group III strains resistant } \\
\text { to penicillin, tetracyclines, } \\
\text { and streptomycin }\end{array}$} & \multicolumn{2}{|c|}{$\begin{array}{l}\text { Strains resistant } \\
\text { to penicillin }\end{array}$} & \multicolumn{2}{|c|}{$\begin{array}{l}\text { Strains resistant } \\
\text { to tetracyclines }\end{array}$} \\
\hline & & Number & Per cent & Number & Per cent & Number & Per cent \\
\hline \multicolumn{8}{|c|}{ Treatment with tetracyclines -25 patients -115 strains } \\
\hline $\begin{array}{c}1-3 \\
4-5 \\
6-7 \\
8-9 \\
10-11 \\
12-13 \\
14-15\end{array}$ & $\begin{array}{r}26 \\
21 \\
19 \\
17 \\
13 \\
11 \\
8\end{array}$ & $\begin{array}{r}4 \\
19 \\
15 \\
14 \\
8 \\
11 \\
6\end{array}$ & $\begin{array}{c}16.6 \\
90 \\
79 \\
82 \\
61.5 \\
100 \\
75\end{array}$ & $\begin{array}{r}16 \\
19 \\
16 \\
16 \\
11 \\
11 \\
8\end{array}$ & $\begin{array}{l}61.5 \\
90 \\
84 \\
94 \\
84.6 \\
100 \\
100\end{array}$ & $\begin{array}{r}4 \\
19 \\
17 \\
16 \\
10 \\
11 \\
8\end{array}$ & $\begin{array}{l}16.6 \\
90 \\
89.5 \\
94 \\
77 \\
100 \\
100\end{array}$ \\
\hline \multicolumn{8}{|c|}{ Treatment with penicillin, alone or with streptomycin -30 patients -135 strains } \\
\hline $\begin{array}{c}1-3 \\
4-5 \\
6-7 \\
8-9 \\
10-11 \\
12-13 \\
14-15\end{array}$ & $\begin{array}{l}28 \\
10 \\
17 \\
20 \\
20 \\
23 \\
17\end{array}$ & $\begin{array}{r}5 \\
0 \\
5 \\
13 \\
13 \\
16 \\
14\end{array}$ & $\begin{array}{l}18.5 \\
0 \\
29.2 \\
65 \\
65 \\
70 \\
82.4\end{array}$ & $\begin{array}{r}18 \\
5 \\
13 \\
18 \\
19 \\
22 \\
17\end{array}$ & $\begin{array}{l}66.6 \\
55 \\
76.5 \\
90 \\
95 \\
95 \\
100\end{array}$ & $\begin{array}{r}5 \\
0 \\
5 \\
13 \\
14 \\
16 \\
15\end{array}$ & $\begin{array}{l}18.5 \\
0 \\
29.4 \\
65 \\
70 \\
69.4 \\
88.4\end{array}$ \\
\hline \multicolumn{8}{|c|}{ No antimicrobial treatment -13 patients -54 strains } \\
\hline $\begin{array}{c}1-3 \\
4-5 \\
6-7 \\
8-9 \\
10-11 \\
12-13 \\
14-15\end{array}$ & $\begin{array}{r}13 \\
8 \\
5 \\
9 \\
7 \\
8 \\
4\end{array}$ & $\begin{array}{l}0 \\
0 \\
1 \\
0 \\
3 \\
2 \\
0\end{array}$ & $\begin{array}{r}0 \\
0 \\
20 \\
0 \\
43 \\
25 \\
0\end{array}$ & $\begin{array}{l}8 \\
4 \\
4 \\
5 \\
5 \\
6 \\
3\end{array}$ & $\begin{array}{l}61.5 \\
50 \\
80 \\
55.5 \\
71.3 \\
75 \\
75\end{array}$ & $\begin{array}{l}0 \\
0 \\
1 \\
1 \\
4 \\
2 \\
0\end{array}$ & $\begin{array}{r}0 \\
0 \\
20 \\
11 \\
57 \\
25 \\
0\end{array}$ \\
\hline
\end{tabular}

Statistical analysis: (Chi-square test)

4- to 5-day period

4- to 9-day period
Penicillin resistance in penicillin treatment group compared to penicillin resistance in tetracycline treatment group

Per cent "hospital staphylococci" in penicillin treatment group compared to tetracycline treatment group; per cent in penicillin treatment group compared to no antimicrobial treatment group
Probability of chance occurrence $<0.02$

Probability of chance occurrence $<0.01$ less rapid change, while only a moderate increase in the percentage of the strains of "hospital staphylococci" occurred among patients who received no antibiotics.

\section{REFERENCES}

1. Williams, R. E. O., and Rippon, J. E., Bacteriophage typing of strains of Staphylococcus aureus from various sources. Lancet, 1953, 1, 510.

2. Rountree, P. M., and Thomson, E. F., Incidence of antibiotic-resistant staphylococci in a hospital. Lancet, 1952, 2, 262.

3. Rountree, P. M., Bacteriophage typing of strains of staphylococci isolated in Australia. Lancet, 1953, $1,514$.

4. Vogelsang, T. M., Staphylococcal studies in hospital staffs. III. Bacteriophage typing. Acta Path. et Microbiol. Scandinav., 1953, 33, 435.

5. Fusillo, M. H., Roerig, R. N., Metzger, J. F., and Ernst, K. F., I. Phage typing the antibiotic-resistant staphylococci. In press.

6. Jackson, G. G., and Finland, M., Comparison of methods for determining sensitivity of bacteria to antibiotics in vitro. A. M. A. Arch. Int. Med., 1951, $88,446$.

7. Haight, T. H., and Finland, M., Modified Gots test for penicillinase production. Am. J. Clin. Path., 1952, 22, 806.

8. Williams, R. E. O., and Rippon, J. E., Bacteriophage typing of Staphylococcus aureus. J. Hygiene, 1952, $50,320$.

9. Blair, J. E., and Carr, M., The bacteriophage typing of staphylococci. J. Infect. Dis., 1953, 93, 1. 